Check for updates

Cite this: Mater. Adv., 2020 1,441

Received 18th April 2020

Accepted 7th May 2020

DOI: 10.1039/d0ma00222d

rsc.li/materials-advances

\section{New findings and current controversies on oxidation of benzyl alcohol by a copper complex $\dagger$}

\author{
Zahra Zand, ${ }^{a}$ Jitendra Pal Singh, DD $^{\mathrm{b}}$ Robabeh Bagheri, ${ }^{\mathrm{c}}$ Junfeng Cui, de \\ Keun Hwa Chae, (D) ${ }^{b}$ Zhenlun Song (D) ${ }^{c}$ and Mohammad Mahdi Najafpour (D)*afg
}

Herein, we report new findings and details for the alcohol-oxidizing activity of a copper complex in the presence of molecular oxygen. Using scanning electron microscopy, transmission electron microscopy, UV-vis spectroscopy, Fourier transform infrared spectroscopy, X-ray absorption near edge structure, extended X-ray absorption fine structure, and X-ray diffraction, it is suggested that the true catalyst for the reaction is a copper complex mixed with potassium carbonate.

\section{Introduction}

The oxidation of alcohols to carbonyl compounds is an important reaction, which is done typically using permanganate and dichromate salts. These salts are moderately corrosive, unstable, expensive, and toxic and show no selectivity. These salts also require hazardous procedures for preparation and over-oxidation to carboxylic acids is observed in the presence of these oxidants. For the first time, Semmelhack's group used $\mathrm{CuCl}(10 \mathrm{~mol} \%)$ and TEMPO (10 mol\%) to oxidize primary alcohols in the presence of molecular oxygen at room temperature. ${ }^{1}$ In 1996, Marko's group reported an efficient copper-based catalyst that oxidized many alcohols into aldehydes and ketones under mild conditions. ${ }^{2}$ The true catalyst under Marko's conditions is suggested to be a heterogeneous and adsorbed compound on $\mathrm{K}_{2} \mathrm{CO}_{3}$. Such oxidation reactions have been performed using many copper complexes with different ligands. ${ }^{3-42}$

${ }^{a}$ Department of Chemistry, Institute for Advanced Studies in Basic Sciences (IASBS), Zanjan, 45137-66731, Iran. E-mail: mmnajafpour@iasbs.ac.ir; Tel: +982433153201

${ }^{b}$ Advanced Analysis Center, Korea Institute of Science and Technology (KIST), Seoul 02792, Republic of Korea

${ }^{c}$ Key Laboratory of Marine Materials and Related Technologies, Ningbo Institute of Materials Technology and Engineering, Chinese Academy of Sciences, Ningbo 315201, China

${ }^{d}$ Key Laboratory for Precision and Non-Traditional Machining Technology of Ministry of Education, Dalian University of Technology, Dalian 116024, China

${ }^{e}$ Surface Protection Research Group, Surface Department, Ningbo Institute of Materials Technology and Engineering, Chinese Academy of Sciences, 519 Zhuangshi Road, Ningbo 315201, China

${ }^{f}$ Center of Climate Change and Global Warming, Institute for Advanced Studies in Basic Sciences (IASBS), Zanjan, 45137-66731, Iran

${ }^{g}$ Research Center for Basic Sciences \& Modern Technologies (RBST), Institute for Advanced Studies in Basic Sciences (IASBS), Zanjan 45137-66731, Iran

$\dagger$ Electronic supplementary information (ESI) available. See DOI: 10.1039/ d0ma00222d
Marko's group proposed that an initial hydrogen-transfer reaction within the copper-alkoxide/azo complex generates the carbonyl-bound hydrazino-copper species, which produces a binuclear copper(II) peroxide upon reaction with oxygen. After homolytic cleavage followed by a hydrogen-atom abstraction, the hydroxy $\mathrm{Cu}(\mathrm{I})$ complex is formed (Scheme 1). The rapid exchange between the $\mathrm{OH}$ ligand and the alcohol regenerates the catalyst (Scheme 1).

The clear role of $\mathrm{K}_{2} \mathrm{CO}_{3}$ or the true catalyst is not known; however, some points and questions are:

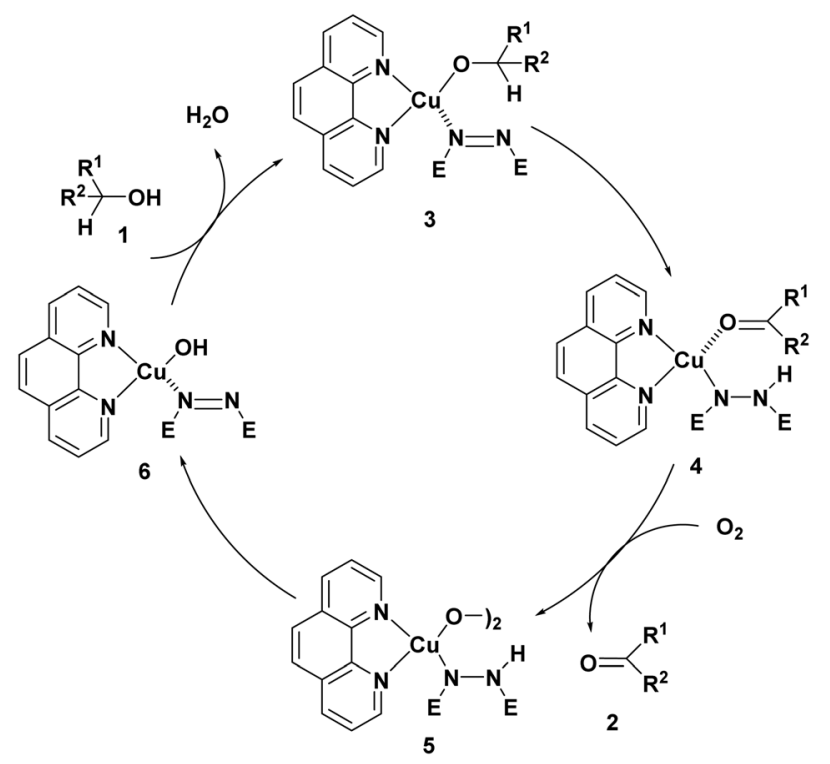

Scheme 1 The proposed mechanism for the alcohol oxidation by Marko's complex. The role of diethylazodicarboxylate is the reduction of the copper(I) complex and the formation of the copper(I) complex. The image is modified from ref. 2 . 
(i) $\mathrm{HCl}$ is formed during this reaction. $\mathrm{K}_{2} \mathrm{CO}_{3}$ is a base and could react with $\mathrm{HCl}$.

(ii) $\mathrm{K}_{2} \mathrm{CO}_{3}$ is a support.

(iii) $\mathrm{K}_{2} \mathrm{CO}_{3}$ could act as a water scavenger.

(iv) What is the role of $\mathrm{K}_{2} \mathrm{CO}_{3}$ ?

(v) What is the true catalyst: Marko's complex, a $\mathrm{Cu}$ (II) complex, $\mathrm{CuCl}_{2}$, or $\mathrm{CuCl}$ ?

(vi) What is the nature of the dark copper-based compound on $\mathrm{K}_{2} \mathrm{CO}_{3}$ ?

The finding of the true catalyst is important to design and synthesize new, stable, and efficient catalysts. In 2010, Liang et al. reported a procedure using "copper(II) chloride-cesium carbonate" to aerobically oxidize primary alcohols. ${ }^{43} \mathrm{Cs}_{2} \mathrm{CO}_{3}$ and the solvents such as toluene and 1,2-dichloroethane play important roles to form a catalytically active intermediate containing a hydroxyl-bridged trinuclear copper moiety. From the X-ray crystal structure of trinuclear copper, an electrostatic interaction between $\mathrm{Cl}^{-}$and $\mathrm{Cs}^{+}$was observed, which stimulated the suggestion of the roles of $\mathrm{Cs}_{2} \mathrm{CO}_{3}$ in this reaction as a base, and stabilizing and "solvating" intermediates in toluene and 1,2-dichloroethane. ${ }^{43}$

In this study, we report new findings for the alcoholoxidizing activity of a Cu complex in the presence of molecular oxygen. Herein, using scanning electron microscopy (SEM), transmission electron microscopy (TEM), UV-vis spectroscopy, Fourier transform infrared spectroscopy (FTIR), X-ray absorption near edge structure (XANES), extended X-ray absorption fine structure (EXAFS), and X-ray diffraction (XRD), it is proposed that the true catalyst for the alcohol oxidation in the presence of Marko's complex is a mixture of the copper complex and
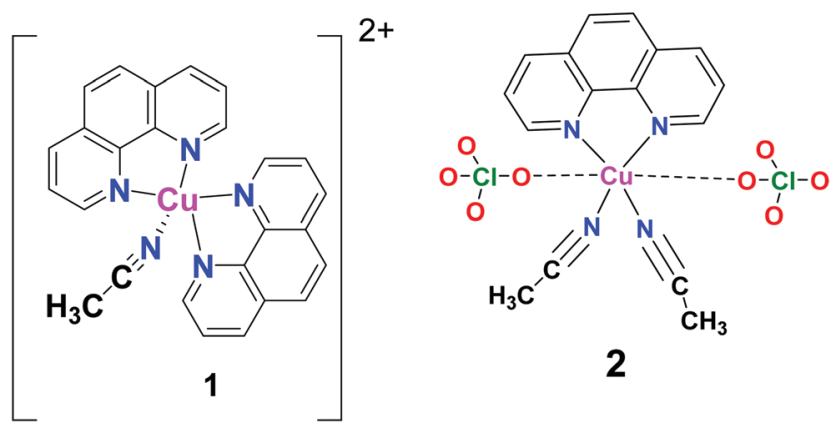

Fig. 1 Schematic structures of $1\left(\left[\mathrm{Cu}\left(\mathrm{C}_{12} \mathrm{H}_{8} \mathrm{~N}_{2}\right)_{2}\left(\mathrm{CH}_{3} \mathrm{CN}\right)\right]\left(\mathrm{ClO}_{4}\right)_{2}\right)$ and 2 $\left(\left[\mathrm{Cu}\left(\mathrm{ClO}_{4}\right)\left(\mathrm{C}_{12} \mathrm{H}_{8} \mathrm{~N}_{2}\right)\left(\mathrm{CH}_{3} \mathrm{CN}\right)_{2}\right] \mathrm{ClO}_{4}\right){ }^{44,45}$

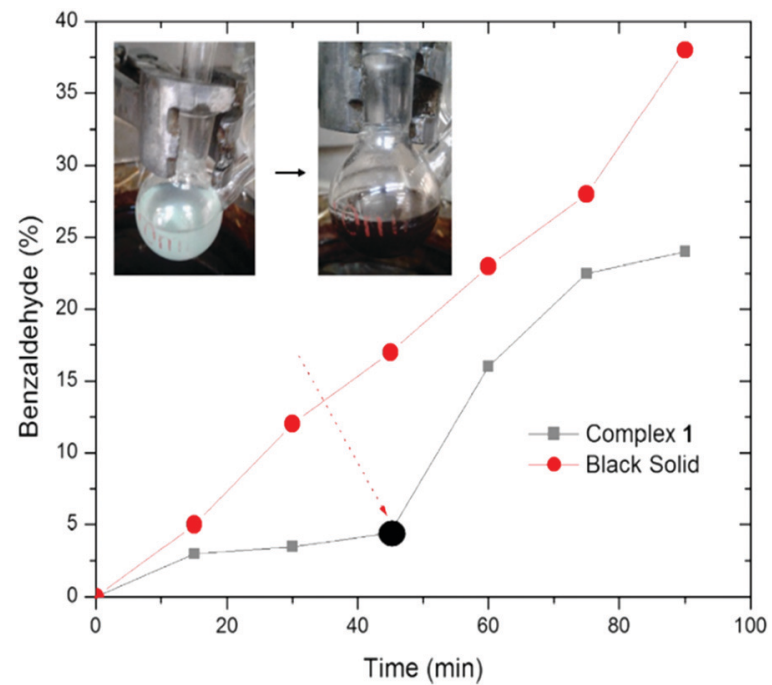

Fig. 2 The reaction profiles of benzaldehyde formation by 1 and the centrifuged nanoparticles from the reaction of 1 . The dark circle shows the time for the dark solid.

potassium carbonate particles rather than nanosized copper oxide or copper carbonate.

\section{Experimental}

\section{Materials and methods}

See the ESI. $\dagger$

Synthesis of the complex. 1 was prepared by the reaction of 1,10-phenanthroline (Phen) monohydrate $(0.40 \mathrm{~g}, 2.0 \mathrm{mmol})$ and $\mathrm{Cu}\left(\mathrm{ClO}_{4}\right)_{2} \cdot 6 \mathrm{H}_{2} \mathrm{O}(0.37 \mathrm{~g} ; 1.0 \mathrm{mmol})$ in $30.0 \mathrm{~mL}$ of acetonitrile at room temperature (Fig. 1) ${ }^{44} 2$ was synthesized by the reaction of $\mathrm{Cu}\left(\mathrm{ClO}_{4}\right)_{2} \cdot 6 \mathrm{H}_{2} \mathrm{O}(0.37 \mathrm{~g}, 1 \mathrm{mmol})$ and Phen $(0.20 \mathrm{~g}$, $1 \mathrm{mmol}$ ) in acetonitrile $(40.0 \mathrm{~mL})$ (Fig. 1). ${ }^{45}$

\section{Catalytic procedure}

The catalytic activity of 1 in the alcohol-oxidation reaction. The alcohol-oxidation procedure using 1 or 2 was carried out in an oxygenic atmosphere at $80{ }^{\circ} \mathrm{C}$. In a typical experiment, diisopropyl azodicarboxylate (DIAD; $5 \mathrm{mmol} \%$ ), benzyl alcohol (1.0 mmol), 1 or $2(5.0 \mathrm{mmol} \%)$, and $\mathrm{K}_{2} \mathrm{CO}_{3}(0.27 \mathrm{~g}, 2.0 \mathrm{mmol})$ were stirred in $5.0 \mathrm{~mL}$ of oxygen saturated toluene in a $10.0 \mathrm{~mL}$ two-neck round-bottom flask equipped with an oxygen balloon. The solution was stirred at $80{ }^{\circ} \mathrm{C}$ for $90 \mathrm{~min}$.

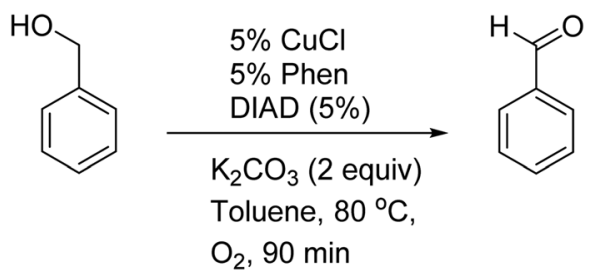

a

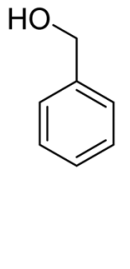

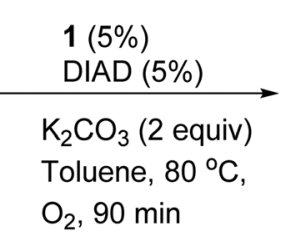<smiles>O=Cc1ccccc1</smiles>

b

Scheme 2 Schematic conditions of the alcohol-oxidation reaction: Marco's reaction (a) and in the presence of 1 under Marco's reaction conditions (b). 


\section{Results and discussion}

Recently, some studies have addressed the mechanism of oxidation by Marko's complex. ${ }^{46}$ However, more investigation on the true catalyst for this reaction is essential. A question is whether $\mathrm{Cu}$ (II) complexes with Phen ligands are active for the oxidation of benzyl alcohol to benzaldehyde under Marko's conditions or not. The oxidation of benzyl alcohol to benzaldehyde using $\mathrm{K}_{2} \mathrm{CO}_{3}$ as a base and $\mathbf{1}$ as the catalyst was selected as the model reaction following Marco's report in 1996. $^{2}\left[\mathrm{Cu}(\mathrm{Phen})_{2} \mathrm{CH}_{3} \mathrm{CN}\left(\mathrm{ClO}_{4}\right)_{2}\right]$ (1) was simply obtained by the reaction of 1 , Phen and $\mathrm{Cu}\left(\mathrm{ClO}_{4}\right)_{2}$ in a $1: 1$ ratio, and blue-green crystals were grown in $\mathrm{CH}_{3} \mathrm{CN}$. The crystal structure of 1 comprises two Phen ligands and one acetonitrile coordinated to $\mathrm{Cu}^{\mathrm{II}}$ lying in a distorted square-pyramidal geometry (Fig. 1). ${ }^{44,45}$

First, Marco's reaction was performed (Scheme 2a). As previously reported, ${ }^{2}$ the formation of a dark solid adsorbed on $\mathrm{K}_{2} \mathrm{CO}_{3}$ was observed, and alcohol oxidation was detected. 2 was inactive for the alcohol-oxidation reaction. However, 1 indicated alcohol-oxidizing activity in the presence of molecular oxygen (Scheme 2b) according to Marko's report.

First, the color of the solution of $\mathbf{1}$ in toluene is light green, but after 45 minutes under conditions similar to Marko's conditions (Scheme 2b) the color turns dark (Fig. S1, ESI $\dagger$ ). The profile of the reaction was monitored by gas chromatography (Fig. 2). In the first $45 \mathrm{~min}$, the alcohol-oxidation

Table 1 Benzyl alcohol oxidation by the catalyst, and the centrifuged nanoparticles from the reaction

Entry Catalyst Benzyl alcohol (\%) $\quad$ Benzaldehyde (\%) $\quad$ Conditions

$1 \mathrm{CuCl}$

22

78

Complex (2)

Complex (1)

Centrifuged solid from the reaction of entry 1

62

5

$\mathrm{Cu}\left(\mathrm{ClO}_{4}\right)_{2}$

85

15

$\mathrm{CuCl}$

99-95

$1-5$

7

CuI

99-95

1-5
CuI

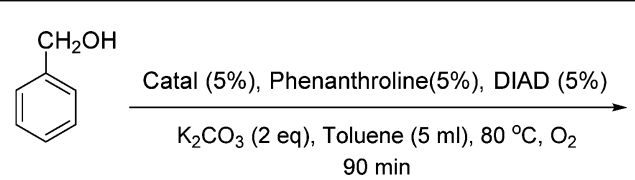<smiles>O=Cc1ccccc1</smiles><smiles>OCc1ccccc1</smiles>

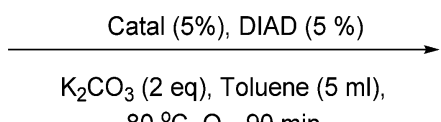<smiles>O=Cc1ccccc1</smiles>
$80^{\circ} \mathrm{C}, \mathrm{O}_{2}, 90 \mathrm{~min}$<smiles>OCc1ccccc1</smiles>

Catal (5\%), DIAD (5 \%)

$\mathrm{K}_{2} \mathrm{CO}_{3}$ (2 eq), Toluene $(5 \mathrm{ml})$ $80^{\circ} \mathrm{C}, \mathrm{O}_{2}, 90 \mathrm{~min}$

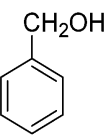

Catal (5\%), DIAD (5\%)

$\mathrm{K}_{2} \mathrm{CO}_{3}$ (2 eq), Toluene $(5 \mathrm{ml})$ $80^{\circ} \mathrm{C}, \mathrm{O}_{2}, 90 \mathrm{~min}$

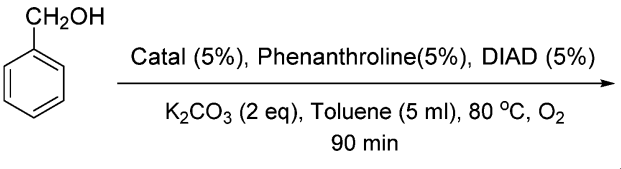<smiles>O=Cc1ccccc1</smiles><smiles>OCc1ccccc1</smiles>

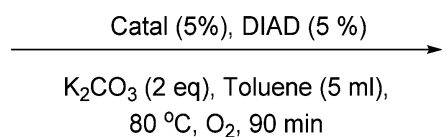<smiles>O=Cc1ccccc1</smiles><smiles>OCc1ccccc1</smiles>

Catal (5\%), DIAD (5\%)

$\mathrm{K}_{2} \mathrm{CO}_{3}$ (2 eq), Toluene $(5 \mathrm{ml})$,<smiles>O=Cc1ccccc1</smiles><smiles>O=Cc1ccccc1</smiles>
$80^{\circ} \mathrm{C}, \mathrm{O}_{2}, 90 \mathrm{~min}$

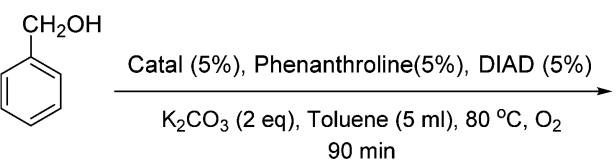<smiles>O=Cc1ccccc1</smiles> 
reaction is slow, but after the formation of a dark solid, an increase in the activity was observed. The highest yield of benzaldehyde ( $\sim 23 \%$ ) was measured after 90 min. An important question in this regard is whether the dark solid is a true catalyst or a product of decomposition? The obtained dark precipitate was separated, rinsed three times with toluene, and resuspended in toluene and benzyl alcohol $(\mathrm{BnOH})$ in the presence of $\mathrm{O}_{2}$ at $80{ }^{\circ} \mathrm{C}$ (Fig. 2). Immediately, benzaldehyde
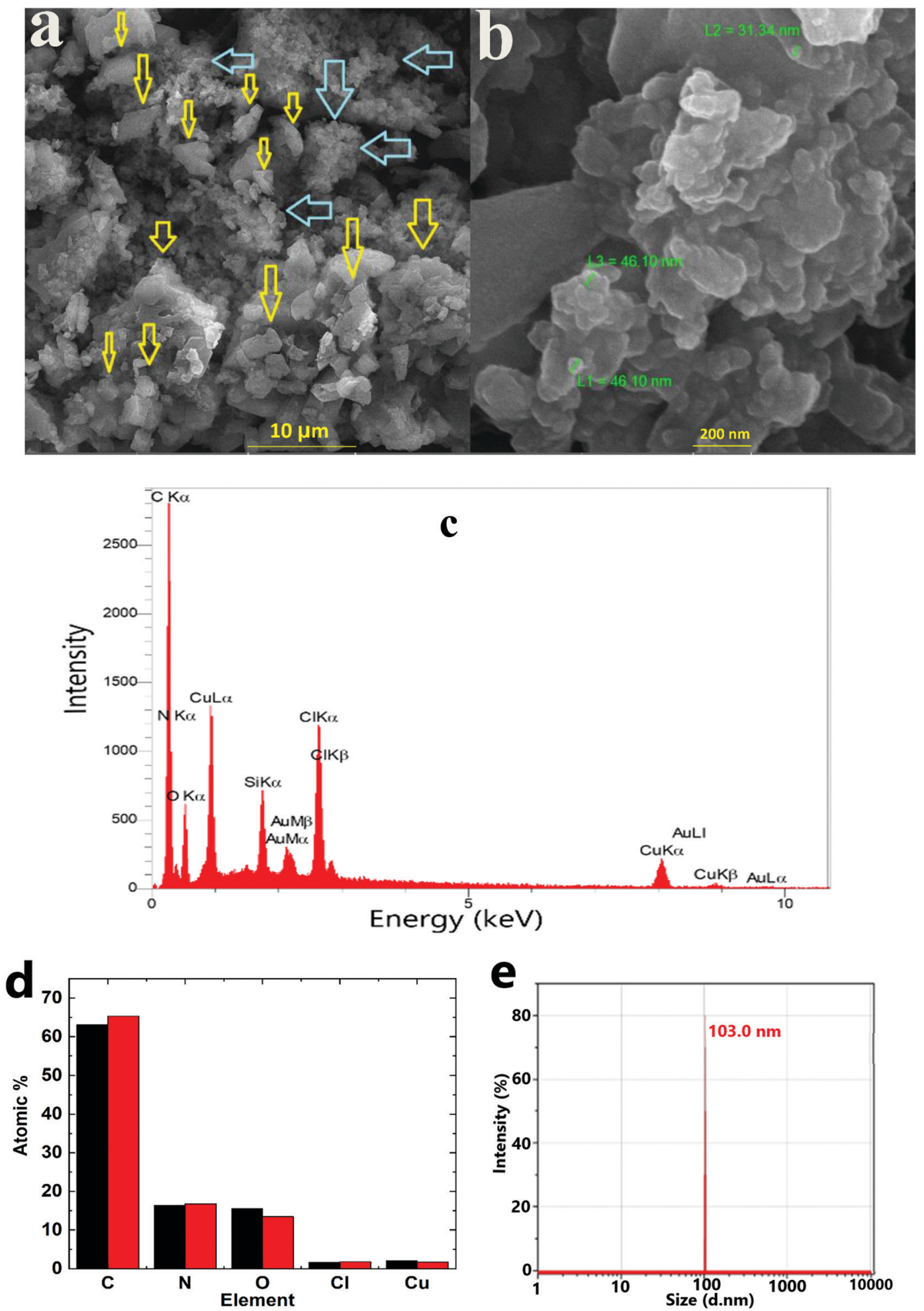

Fig. 3 SEM images (a and b), EDX spectrum (c) and EDX results for two points (d). DLS (e) of solid 1 under Marko's conditions. Yellow and blue arrows show two different morphologies. 

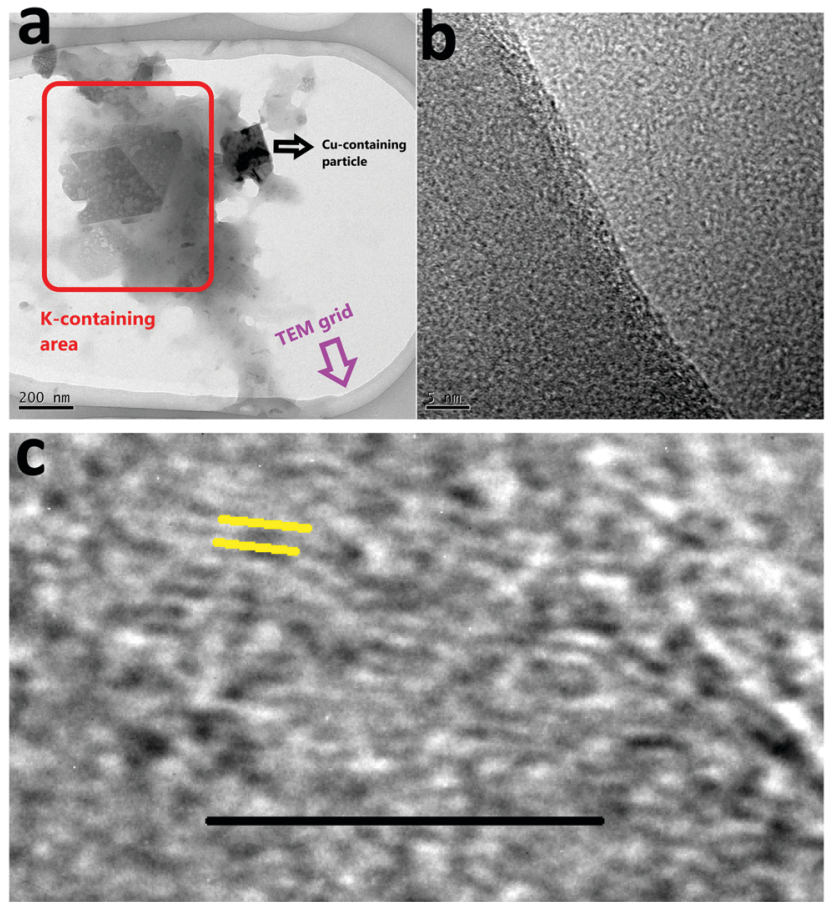

Fig. 4 TEM (a) and (HR)TEM ( $b$ and $c$ ) of solid 1 under Marko's conditions. The scale bar in image (c) is $5 \mathrm{~nm}$.

formation was observed, and the yield was $38 \%$ at $90 \mathrm{~min}$. The result showed that this dark precipitate could perform the alcohol-oxidation reaction as a catalyst (Fig. 2). As shown in Table S1 (ESI $\dagger$ ), CuO in the presence and absence of Phen could not oxidize benzyl alcohol.

As shown by Marko, ${ }^{2}$ azo compounds, such as diethyl azodicarboxylate or its analog, significantly improve the turnover for alcohol oxidation, the lifetime of the catalyst, and also the rate of the reaction. The role of DIAD is the reduction of the copper(II) complex and the formation of the copper(I) complex.

2 was not a catalyst under Marko's conditions (Table 1; for a complete table see Table S1, ESI, $\dagger$ entry 2 ), but 1 (entry 3 ) or the centrifuged nanoparticles from the reaction of 1 (solid 1) showed activity for the alcohol-oxidation reaction (entry 4). Replacing $\mathrm{CuCl}$ by $\mathrm{Cu}\left(\mathrm{ClO}_{4}\right)_{2}$ in Marko's reaction resulted in low activity for the alcohol-oxidation reaction (entry 5). No activity was observed in the presence of $\mathrm{CuCl}$ or $\mathrm{CuI}$ in the absence of Phen (entries 6 and 7). CuI in the presence of Phen indicated a high activity toward the alcohol-oxidation reaction (entry 8$). \mathrm{K}_{2} \mathrm{Cu}\left(\mathrm{CO}_{3}\right)_{2}$ or $\mathrm{CuCO}_{3}$ in the presence or absence of Phen could not oxidize benzyl alcohol. 1 performed the alcoholoxidation reaction using other bases such as $\mathrm{Na}_{2} \mathrm{CO}_{3}$ and $\mathrm{Cs}_{2} \mathrm{CO}_{3}$, where the conversions of benzyl alcohol were the same. However, a poor conversion was achieved using $\mathrm{Et}_{3} \mathrm{~N}$. These results suggest that mixing the catalyst with $\mathrm{K}_{2} \mathrm{CO}_{3}$ plays an important role to increase the reactivity of the copper complex in alcohol oxidation.

Afterward, the dark solid obtained under the alcoholoxidation reaction by $\mathbf{1}$ was analyzed by SEM, TEM, EDX, and XRD analyses.

The SEM images of the obtained dark solid (solid 1) displayed nanoparticles without any special morphology in an average size of 30-200 nm (Fig. 3a and Fig. S3, ESI $\dagger$ ). Both crystalline and amorphous particles could be detected in the SEM images. These two types of particles were significantly aggregated. According to the XRD patterns, the crystalline particles could be both $\mathrm{K}_{2} \mathrm{CO}_{3} \cdot 1.5 \mathrm{H}_{2} \mathrm{O}$ and 1 (Fig. 3b). Based on the EDX data, in addition to $\mathrm{O}$ and $\mathrm{C}$, the obtained solid contained $\mathrm{Cu}$ and $\mathrm{Cl}$ (Fig. $3 \mathrm{~b}$ and c).

90 min after the reaction of 1 with $\mathrm{K}_{2} \mathrm{CO}_{3}$, the formed particles were separated and investigated by dynamic light scattering (DLS). DLS in water indicated a diameter $\sim 100 \mathrm{~nm}$ for the nanoparticles. Compared with particles in SEM or TEM images, different sized particles were observed in DLS analysis (Fig. 3e). $\mathrm{K}_{2} \mathrm{CO}_{3}$ is soluble in water, and thus only Cu-containing particles could be investigated by DLS.

TEM of solid 1 showed two different particles: K-containing particles (light particles) and Cu-containing particles (dark particles) (Fig. 4a). As shown by the SEM images, these two types of particles were significantly aggregated. In Marko's report, it was suggested that the active catalyst is a heterogeneous catalyst supported on $\mathrm{K}_{2} \mathrm{CO}_{3}{ }^{2}$ The TEM images
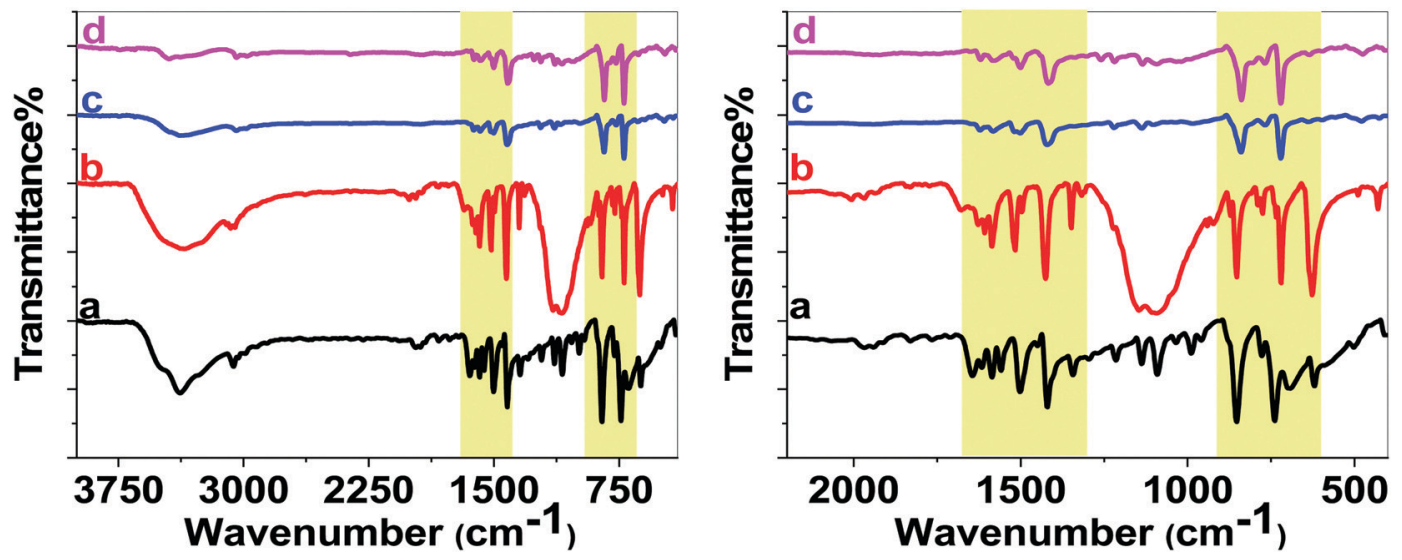

Fig. 5 IR spectra of Phen (a), 1 (b) and solid 1 after a few seconds (c) and after 90 minutes (d) under Marko's conditions in different ranges. 


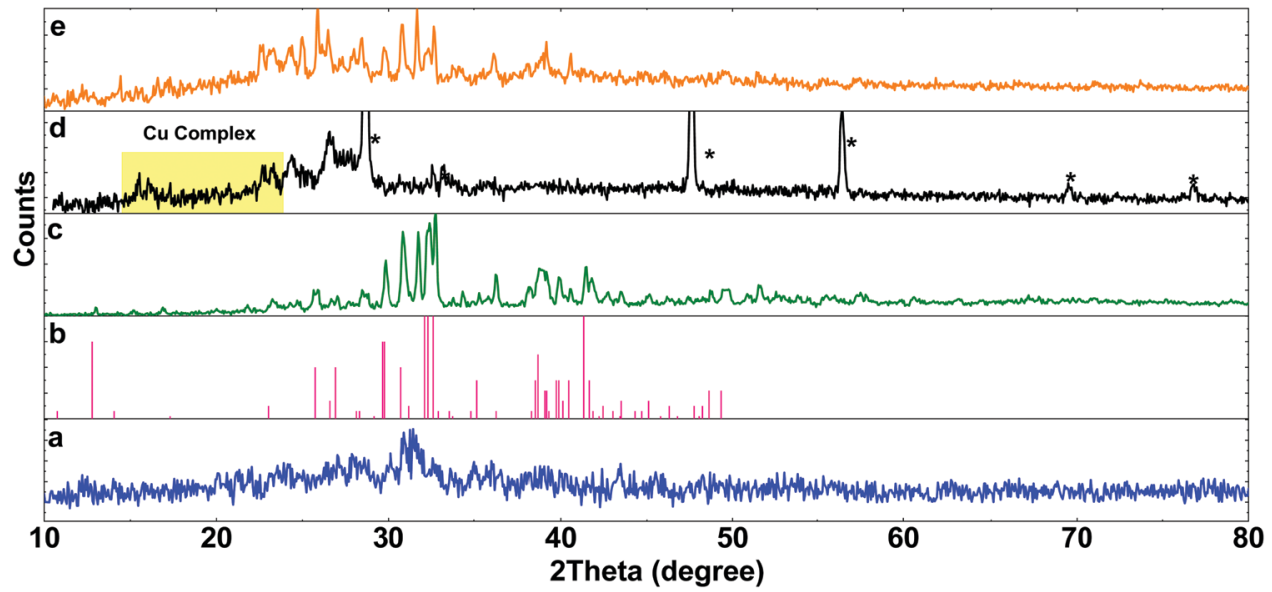

Fig. 6 XRD patterns for 1 (a), $\left(\mathrm{K}_{2} \mathrm{CO}_{3} \cdot 1.5 \mathrm{H}_{2} \mathrm{O}\right)$ (ref. code: 00-011-0655) (b), and solid 1 under Marko's conditions (c). The obtained solid from the mixing of $\mathrm{CuCl}$ and Phen after $30 \mathrm{~min}$ (* is related to $\mathrm{CuCl}$ (ref. code: 01-077-2383)) (d). The obtained solid from the mixing of $\mathrm{CuCl}_{1} \mathrm{Phen}, \mathrm{K}_{2} \mathrm{CO}_{3}, \mathrm{DIAD}$, and $\mathrm{BnOH}$ after 90 min (Marko's report) (e).
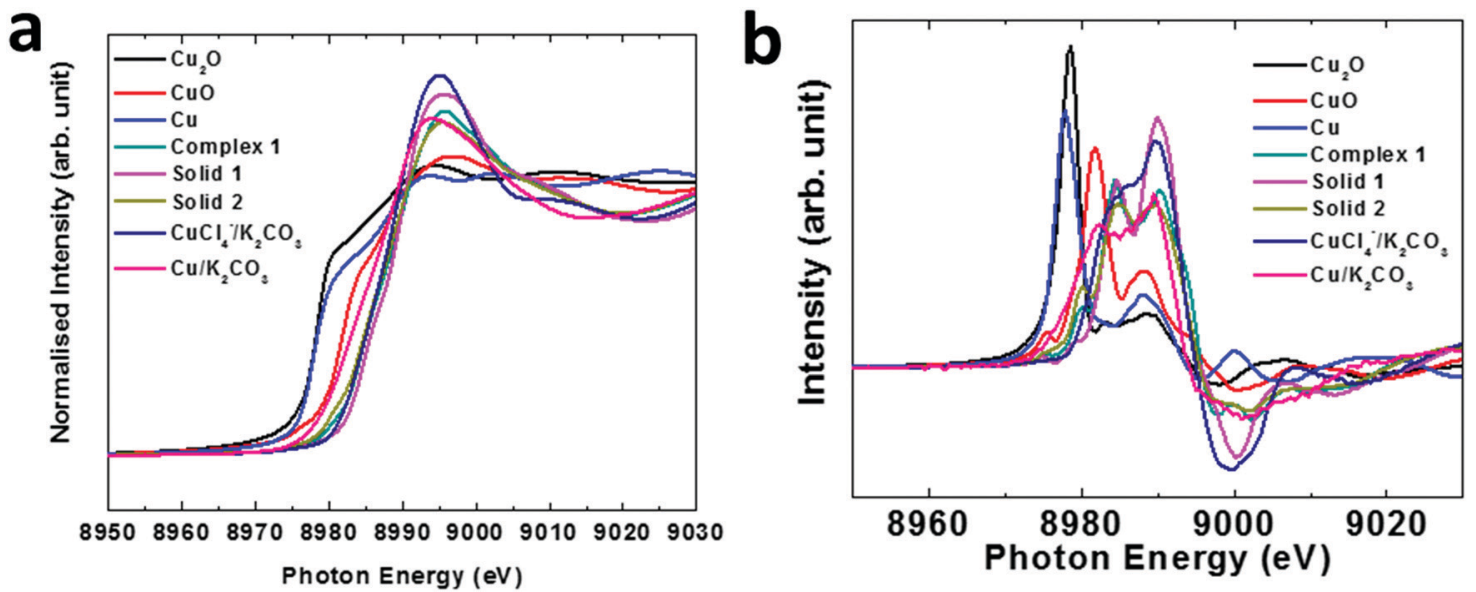

Fig. 7 XANES (a) and the first derivative curve (b) for different compounds.

confirmed the presence of nanoparticles in the size range 50$200 \mathrm{~nm}$ (Fig. 4a). As can be seen, dark nanoparticles ( $c a .100 \mathrm{~nm}$ ) are dispersed among big light particles (Fig. $4 \mathrm{~b}$ and Fig. S4-S7, ESI $\dagger$ ). Thus, TEM images similar to the SEM images showed a mixture of $\mathrm{Cu}$ and K-containing particles for solid $\mathbf{1}$ under Marko's conditions.

The HRTEM image of solid $\mathbf{1}$ showed non-crystallinity of the nanoparticles (Fig. 4b), but in a few areas patterns with a $d$-spacing of $0.27 \mathrm{~nm}$ (Fig. 4c) corresponding to planes in the range $2 \theta: 30-33^{\circ}$ for 1 or $\mathrm{K}_{2} \mathrm{CO}_{3}$ and in agreement with the powder X-ray diffraction (XRD) pattern were observed.

In FTIR spectra for 1 and solid 1, some peaks at 1400$1600 \mathrm{~cm}^{-1}$ were observed that are attributed to $\mathrm{C}=\mathrm{N} / \mathrm{C}=\mathrm{C}$, suggesting the intact structure of $\mathbf{1}$ (Fig. 5). The FTIR spectrum of phenanroline showed the stretching vibration peaks of $\mathrm{C}=\mathrm{N}$ and $\mathrm{C}=\mathrm{C}$ double bonds at $1643 \mathrm{~cm}^{-1}$ and $1583 \mathrm{~cm}^{-1}$ and the skeleton vibration peak at $1555 \mathrm{~cm}^{-1}$, and the out-plane bending vibration peak of $\mathrm{C}-\mathrm{H}$ bonds appears at $734 \mathrm{~cm}^{-1}$. Compared with the spectrum of phenanroline, the stretching vibration peaks for 1 were observed at $1626(\mathrm{C}=\mathrm{N})$ and $1584(\mathrm{C}=\mathrm{C}) \mathrm{cm}^{-1}$. The out-of-plane bending vibration peak of $\mathrm{C}-\mathrm{H}$ bonds also shifts from $735 \mathrm{~cm}^{-1}$ in Phen to $720 \mathrm{~cm}^{-1}$ in the complex. After the reaction, the FTIR spectrum of solid 1 showed related peaks at 1620 and $1583 \mathrm{~cm}^{-1}$ attributed to $\mathrm{C}=\mathrm{N}$ and $\mathrm{C}=\mathrm{C}$ double bonds in the metal complex. The out-of-plane bending vibration peak of $\mathrm{C}-\mathrm{H}$ bonds was also observed at $720 \mathrm{~cm}^{-1}$. $^{47}$ Thus, the FTIR experiment showed that the copper complex in solid $\mathbf{1}$ was intact.

Marko's group also reported that the solution obtained from filtration of the heterogeneous mixture was devoid of any oxidizing ability. Conversely, the obtained precipitate indicated activity for the oxidation reaction.

The XRD patterns also showed the presence of a $\mathrm{Cu}(\mathrm{Phen})$ based-material on $\mathrm{K}_{2} \mathrm{CO}_{3}$ (Fig. 6d and e). It seems that Marko's conditions highly depend on forming $\mathrm{Cu}$ (Phene) in the presence of $\mathrm{K}_{2} \mathrm{CO}_{3}$. When $\mathrm{K}_{2} \mathrm{CO}_{3}$ was added after $\mathrm{Cu}(\mathrm{Phen})$ forming, the conversion of benzyl alcohol was achieved in lower yield ( $35 \%$ in $90 \mathrm{~min})$. 

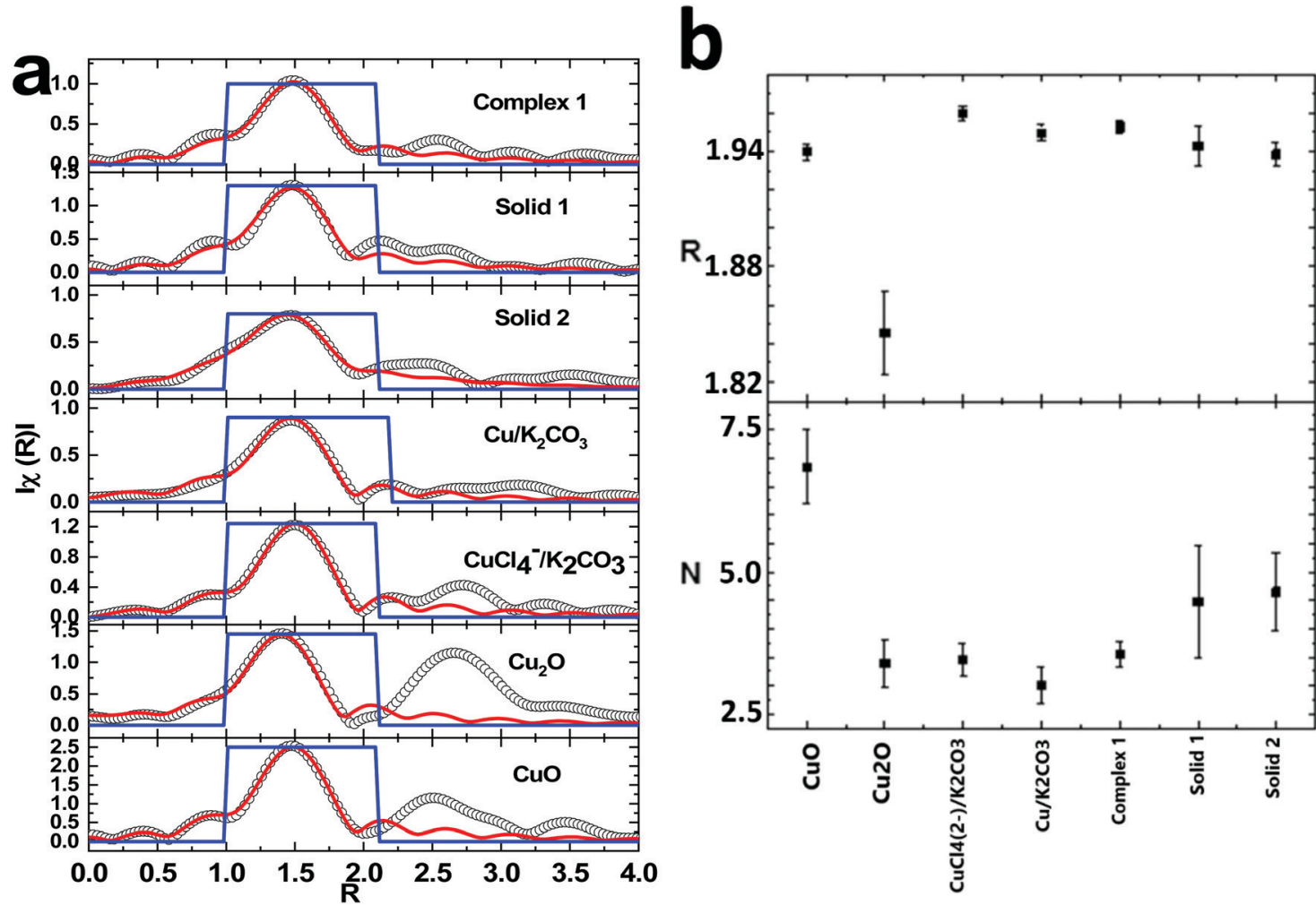

Fig. 8 Inverse Fourier transform spectra of various materials along with oxides (a); coordination number and radial distances for different materials (b).

To further characterize the solid, XANES spectra were used. Fig. 7 illustrates the normalized XANES spectra along with derivative spectra (Fig. 7b) of various compounds.

The main edges of the dark compounds obtained in the reaction of complex 1 and 2 and solid 1 and 2, respectively, along with those of various materials, appear at higher energy than $\mathrm{CuO}$. This reveals that the valence state of $\mathrm{Cu}$ ions is higher than that of 2 . However, this shift is also associated with the presence of the ligand in complex organic systems. ${ }^{48,49}$ Thus, the ligand effect may be one of the reasons for the higher energy shift in these complex systems. The first derivative curve also exhibits a similar effect (Fig. 7b). To get information on bond distances for these materials, these spectra were simulated using a quick shell parameter fit. The fitted inverse Fourier transforms of the EXAFS spectra are shown in Fig. 8a. The values of the coordination number, $N$, and radial distance, $R$, are shown in Fig. $8 \mathrm{~b}$.

Both the experimental and fitted data points are in agreement in the fitting range. The values of the coordination number and radial distances for the $\mathrm{Cu}-\mathrm{O}$ shell for oxides like $\mathrm{CuO}$ and $\mathrm{Cu}_{2} \mathrm{O}$ are similar to reported values. In the case of solids $\mathbf{1}$ and $\mathbf{2}$, the values of the radial distances are $1.94 \pm 0.01$ and $1.938 \pm$ $0.006 \AA$ A, respectively, with the coordination numbers being $4.5 \pm 1.0$ and $4.7 \pm 0.7$, respectively. However, compared to previous reports, the $\mathrm{Cu}-\mathrm{O}$ bonds occur at $2.433 \AA$ with a coordination number of 2 for solid 2 , and $\mathrm{Cu}$ ions are surrounded by $4 \mathrm{~N}$ ion bonds having an average bond distance $\sim 1.98 \AA$, which are comparable to the values estimated for solids $\mathbf{1}$ and $\mathbf{2}$ (Fig. 8b). Thus, these materials contain $\mathrm{Cu}-\mathrm{N}$ bonds. Based on the above observations, we infer that the true catalyst is the $\mathrm{Cu}$ complex mixed with $\mathrm{K}_{2} \mathrm{CO}_{3}$.

Finally, a question posed of Marko's catalyst is why such a system in the presence of a strong base is not efficient for alcohol oxidation. A simple experiment indicated that copper complexes with one Phen ligand such as 2 were simply decomposed or dimerized in the presence of $\mathrm{KOH}$ or $\mathrm{NaOH}$ (Fig. S4, ESI $\dagger$ ). ${ }^{50-53}$ As we showed that a molecular structure is an active species in Marko's system, it is not surprising that strong bases such as $\mathrm{KOH}$ or $\mathrm{NaOH}$ are not appreciated under Marko's conditions. However, the alcohol-oxidation reaction is usually very complicated and other factors could also be important. ${ }^{54,55}$

\section{Conclusions}

Using SEM, TEM, UV-vis spectroscopy, FTIR, XANES, EXAFS, and XRD analyses, we conclude that a $\mathrm{Cu}$ molecule-based complex is the true catalyst for the alcohol-oxidation reaction under Marko's conditions in the presence of molecular oxygen. In the presence of $\mathrm{K}_{2} \mathrm{CO}_{3}$ and 1 , a solid was observed. Characterization of the solid showed that it is a $\mathrm{Cu}$ (II) complex mixed with $\mathrm{K}_{2} \mathrm{CO}_{3}$. It seems that heterogeneous catalysts are more complicated than we thought before.

According to our experiments:

(i) $\mathrm{Cu}$ (I) rather than $\mathrm{Cu}$ (II) is critical for the reaction.

(ii) Phen is important for the reaction. 
(iii) The stable salts such as $\mathrm{CuCO}_{3}, \mathrm{CuO}$ and $\mathrm{K}_{2} \mathrm{Cu}\left(\mathrm{CO}_{3}\right)_{2}$ showed no activity.

(iv) The active catalyst was mixed with $\mathrm{K}_{2} \mathrm{CO}_{3}$.

(v) In Marko's conditions, a Cu(I) complex in the presence of oxygen is oxidized to $\mathrm{Cu}(\mathrm{II})$. It is suggested that the adduct is produced by the reaction of oxygen and the $\mathrm{Cu}(\mathrm{I})$ complex for the alcohol-oxidation reaction because a $\mathrm{Cu}$ (II) complex such as $\mathbf{1}$ or $\mathbf{2}$ is not highly active under Marko's conditions.

(vi) Nanosized $\mathrm{K}_{2} \mathrm{CO}_{3}$ significantly mixed with the complex.

\section{Conflicts of interest}

The authors declare no competing financial interests.

\section{Acknowledgements}

The authors are grateful to the Institute for Advanced Studies in Basic Sciences and the National Elite Foundation for financial support.

\section{References}

1 M. F. Semmelhack, C. R. Schmid, D. A. Cortes and C. S. Chou, J. Am. Chem. Soc., 1984, 106, 3374-3376.

2 I. E. Marko, P. R. Giles, M. Tsukazaki, S. M. Brown and C. J. Urch, Science, 1996, 274, 2044-2046.

3 D. S. Sigman, A. Mazumder and D. M. Perrin, Chem. Rev., 1993, 93, 2295-2316.

4 I. E. Marko, P. R. Giles, M. Tsukazaki, I. Chelle-Regnaut, A. Gautier, R. Dumeunier, F. Philippart, K. Doda, J.-L. Mutonkole and S. M. Brown, Adv. Inorg. Chem., 2004, 56, 211-240.

5 S. E. Allen, R. R. Walvoord, R. Padilla-Salinas and M. C. Kozlowski, Chem. Rev., 2013, 113, 6234-6458.

6 Q. Cao, L. M. Dornan, L. Rogan, N. L. Hughes and M. J. Muldoon, Chem. Commun., 2014, 50, 4524-4543.

7 I. E. Markó, M. Tsukazaki, P. R. Giles, S. M. Brown and C. J. Urch, Angew. Chem., Int. Ed. Engl., 1997, 36, 2208-2210.

8 I. E. Marko, A. Gautier, R. Dumeunier, K. Doda, F. Philippart, S. M. Brown and C. J. Urch, Angew. Chem., Int. Ed., 2004, 43, 1588-1591.

9 P. Gamez, I. W. Arends, R. A. Sheldon and J. Reedijk, Adv. Synth. Catal., 2004, 346, 805-811.

10 E. T. Kumpulainen and A. M. Koskinen, Chem. - Eur. J., 2009, 15, 10901-10911.

11 J. E. Steves and S. S. Stahl, J. Am. Chem. Soc., 2013, 135, 15742-15745.

12 M. T. Musser, Ullmann's Encyclopedia of Industrial Chemistry, Wiley-VCH Verlag GmbH \& Co. KgaA, Weinheim, Germany, 6th edn, 2011, vol. 11, p. 49.

13 D. H. Barton, S. D. Bévière and D. R. Hill, Tetrahedron, 1994, 50, 2665-2670.

14 U. Schuchardt, R. Pereira and M. C. Rufo, J. Mol. Catal. A: Chem., 1998, 135, 257-262.
15 S.-I. Murahashi, Y. Oda, T. Naota and N. Komiya, J. Chem. Soc., Chem. Commun., 1993, 139-140.

16 G. Glatz, T. Schmalz, T. Kraus, F. Haarmann, G. Motz and R. Kempe, Chem. - Eur. J., 2010, 16, 4231-4238.

17 C. Evangelisti, G. Vitulli, E. Schiavi, M. Vitulli, S. Bertozzi, P. Salvadori, L. Bertinetti and G. Martra, Catal. Lett., 2007, 116, 57-62.

18 T. Balandina, T. Y. Larina, N. Kuznetsova and B. Bal'zhinimaev, Kinet. Catal., 2008, 49, 499-505.

19 G. B. Shul'pin, M. M. Bochkova and G. V. Nizova, J. Chem. Soc., Perkin Trans. 2, 1995, 1465-1469.

20 K. Takaki, J. Yamamoto, K. Komeyama, T. Kawabata and K. Takehira, Bull. Chem. Soc. Jpn., 2004, 77, 2251-2255.

21 Y. Li, M. Wu, W. Liu, Z. Yi and J. Zhang, Catal. Lett., 2008, 123, 123-128.

22 I. E. Markó, A. Gautier, I. Chellé-Regnaut, P. R. Giles, M. Tsukazaki, C. J. Urch and S. M. Brown, J. Org. Chem., 1998, 63, 7576-7577.

23 Y. Kurusu and D. Neckers, J. Org. Chem., 1991, 56, 1981-1983. 24 T. Tsuritani, N. A. Strotman, Y. Yamamoto, M. Kawasaki, N. Yasuda and T. Mase, Org. Lett., 2008, 10, 1653-1655.

25 Y. Li, L. X. Gao and F. S. Han, Chem. - Eur. J., 2010, 16, 7969-7972.

26 X. Q. Yu, Y. Yamamoto and N. Miyaura, Chem. - Asian J., 2008, 3, 1517-1522.

27 K. Nishiura, Y. Urawa and S. Soda, Adv. Synth. Catal., 2004, 346, 1679-1684.

28 A. Deagostino, C. Prandi, C. Zavattaro and P. Venturello, Eur. J. Org. Chem., 2007, 1318-1323.

29 T. D. Quach and R. A. Batey, Org. Lett., 2003, 5, 4397-4400.

30 G. W. Kabalka and L.-L. Zhou, Lett. Org. Chem., 2006, 3, 320-323.

31 N. Joubert, E. Baslé, M. Vaultier and M. Pucheault, Tetrahedron Lett., 2010, 51, 2994-2997.

32 Y. Bolshan and R. A. Batey, Angew. Chem., Int. Ed., 2008, 47, 2109-2112.

33 Y. Bolshan and R. A. Batey, Tetrahedron, 2010, 66, 5283-5294.

34 A. Y. Fedorov and J.-P. Finet, Tetrahedron Lett., 1999, 40, 2747-2748.

35 R.-J. Song, C.-L. Deng, Y.-X. Xie and J.-H. Li, Tetrahedron Lett., 2007, 48, 7845-7848.

36 R. Keder, H. Dvořáková and D. Dvořák, Eur. J. Org. Chem., 2009, 1522-1531.

37 A. K. Bakkestuen and L.-L. Gundersen, Tetrahedron Lett., 2003, 44, 3359-3362.

38 S. Benard, L. Neuville and J. Zhu, Chem. Commun., 2010, 46, 3393-3395.

39 P. Y. Lam, D. Bonne, G. Vincent, C. G. Clark and A. P. Combs, Tetrahedron Lett., 2003, 44, 1691-1694.

40 S. Yu, J. Saenz and J. K. Srirangam, J. Org. Chem., 2002, 67, 1699-1702.

41 W. Li, Y. Fan, Y. Xia, P. Rocchi, R. Zhu, F. Qu, J. Neyts, J. L. Iovanna and L. Peng, Helv. Chim. Acta, 2009, 92, 1503-1513.

42 Y. Hari, Y. Shoji and T. Aoyama, Tetrahedron Lett., 2005, 46, 3771-3774. 
43 L. Liang, G. Rao, H.-L. Sun and J.-L. Zhang, Adv. Synth. Catal., 2010, 352, 2371-2377.

44 M.-D. Şerb, B. Calmuschi-Cula, F. Dumitru, T. Dols, U. Englert and C. Guran, Acta Crystallogr., Sect. E: Struct. Rep. Online, 2007, 63, m1292-m1293.

45 M. D. Şerb, C. Guran, F. Dumitru, U. Englert and B. CalmuschiCula, Acta Crystallogr., Sect. E: Struct. Rep. Online, 2007, 63, m1484-m1486.

46 S. D. McCann and S. S. Stahl, J. Am. Chem. Soc., 2016, 138, 199-206.

47 X. Wang, G. Jia, Y. Yu, Y. Gao, W. Zhang, H. Wang, Z. Cao and J. Liu, Quim. Nova, 2015, 38, 298-302.

48 T. L. Daulton and B. J. Little, Ultramicroscopy, 2006, 106, 561-573.
49 M. Tromp, J. Moulin and G. Reid, J. Evans, In AIP Conference Proceedings, 2007, 882, 699-701.

50 B. N. Figgis, R. Mason, A. R. Smith, J. N. Varghese and G. A. Williams, J. Chem. Soc., Dalton Trans., 1983, 703-711.

51 C. Harris and E. McKenzie, J. Inorg. Nucl. Chem., 1967, 29, 1047-1068.

52 D. Perrin and V. Sharma, J. Inorg. Nucl. Chem., 1966, 28, 1271-1278.

53 S. Mahadevan and M. Palaniandavar, Inorg. Chem., 1998, 37, 3927-3934.

54 M. Wang, F. Wang, J. Ma, M. Li, Z. Zhang, Y. Wang, X. Zhang and J. Xu, Chem. Commun., 2014, 50, 292-294.

55 A. Abad, P. Concepción, A. Corma and H. García, Angew. Chem., Int. Ed., 2005, 44, 4066-4069. 